\title{
Evaluation of reference genes for quantitative PCR analysis during somatic embryogenesis in conifers
}

\author{
José Javier de Vega-Bartol", Raissa Raquel Santos, Marta Simões, Celia Miguel \\ From IUFRO Tree Biotechnology Conference 2011: From Genomes to Integration and Delivery \\ Arraial d Ajuda, Bahia, Brazil. 26 June - 2 July 2011
}

Clonal propagation by somatic embryogenesis (SE) has a great application potential in conifers, but its efficiency still needs further improvement. Quantitative PCR (qPCR) is widely used for gene expression analysis during $\mathrm{SE}$ as part of studies to characterize gene function. In $\mathrm{qPCR}$, data is normalized against a reference gene with a uniform expression during the tested conditions. Studies have shown that no single housekeeping gene is universal for all experiments, so a systematic characterization of several endogenous genes for concrete conditions is fundamental for biological accuracy.

We evaluated 10 genes present in Pinus pinaster selected among those commonly used as endogenous reference in conifers (actin, $\alpha$-tubulin, elongation factor $1 \alpha$, adenosine kinase and ubiquitin), previously tested in model plants (Histone 3, SAND protein and clathrim adaptor complex -CAC- subunit), and with a lower variation of expression in five RNA samples at different embryogenesis stages according to microarray hybridization results (homologous to a heat shock protein -HEATSK- and to an ether reductase -REDUC-) (Simões et al., unpublished results). Stability of the expression in three developmental stages (embryogenic tissue in proliferation, mature embryos and germinated embryos) was evaluated with two different algorithms (implemented by programs geNorm and Normfinder), both in Pinus pinaster and Picea abies, so results could be expanded to other conifers. Previously, efficiency was calculated with programs Linreg and qPCR miner and the distribution of Cts by statistical boxplot analysis, for each amplicon.
Results evidenced that the geometric averaging of twoto-four of these genes is accurate enough. Using genes elongation factor $1 \alpha$, SAND and $\alpha$-tubulin as reference is the better generic combination, and so probably the preferable option to consider in other conifers. Among them, SAND and $\alpha$-tubulin had a reduced range of Cts, while it was higher in elongation factor $1 \alpha$, especially in Pinus pinaster. Some discrepancies were detected in the ranking base on stability for the other genes, so this generic combination can be improved in certain stages or species, like adenosine kinase in Pinus pinaster or CAC when analysing embryogenic tissue in proliferation. Adenosine kinase and ubiquitin are also acceptable options, as they showed small ranges of Cts and medium stability values in the three stages in both species. By contrast, several genes showed a higher variation in our experiments, as both selected from the microarray analysis (REDUC and HEATSK), and one commonly used reference gene (actin), which evidence the importance of these kind of studies.

\section{Acknowledgements}

This work has been supported by Fundação para a Ciência e Tecnologia (FCT, Portugal) through projects PTDC/AGR-GPL/102877/2008, P-KBBE/AGRGPL/0001/2009 and grant SFRH/BD/32037/2006 (MS).

Published: 13 September 2011

doi:10.1186/1753-6561-5-S7-044

Cite this article as: Javier de Vega-Bartol et al:: Evaluation of reference genes for quantitative PCR analysis during somatic embryogenesis in conifers. BMC Proceedings 2011 5(Suppl 7):O44.

\footnotetext{
* Correspondence: devegabartol@itqb.unl.pt

Instituto de Biologia Experimental e Tecnológica/Instituto de Tecnologia

Química e Biológica-Universidade Nova de Lisboa (IBET/ITQB-UNL), Portugal
}

( 2011 Javier de Vega-Bartol et al; licensee BioMed Central Ltd. This is an open access article distributed under the terms of the Creative Commons Attribution License (http://creativecommons.org/licenses/by/2.0), which permits unrestricted use, distribution, and reproduction in any medium, provided the original work is properly cited. 